\title{
Notes on the vocalizations of African Citril (Serinus citrinelloides)
}

Peter Boesman

In the following we briefly analyze and compare voice of the different races of African Citril (Serinus citrinelloides). We also try to quantify the extent of any vocal differences using the criteria proposed by Tobias et al. (2010), as a support for taxonomic review. We have made use of sound recordings available on-line from Xeno Canto (XC) and Macaulay Library (ML).

An overview of song per race, illustrated with sonograms:

C Ethiopia (nominate)

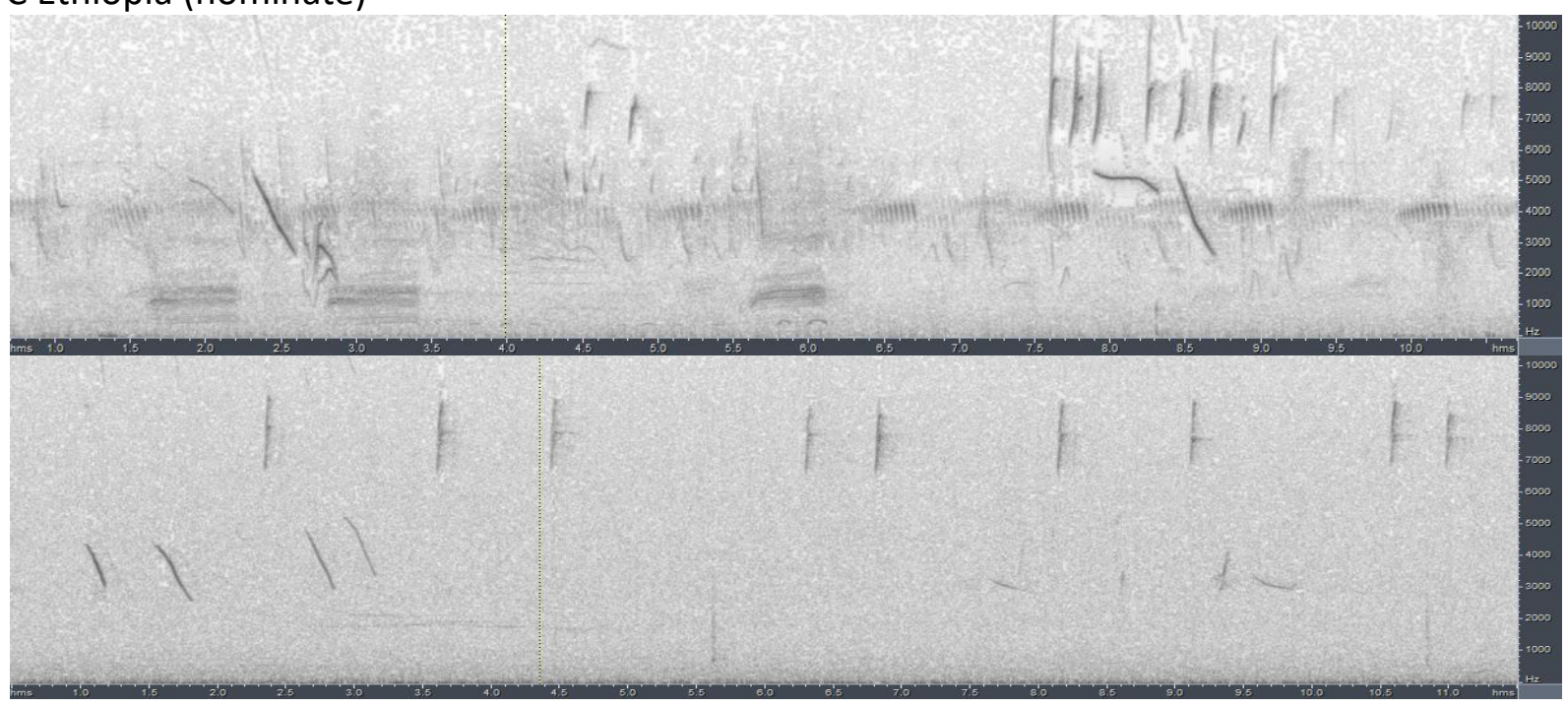

Nairobi (kikuyensis?)

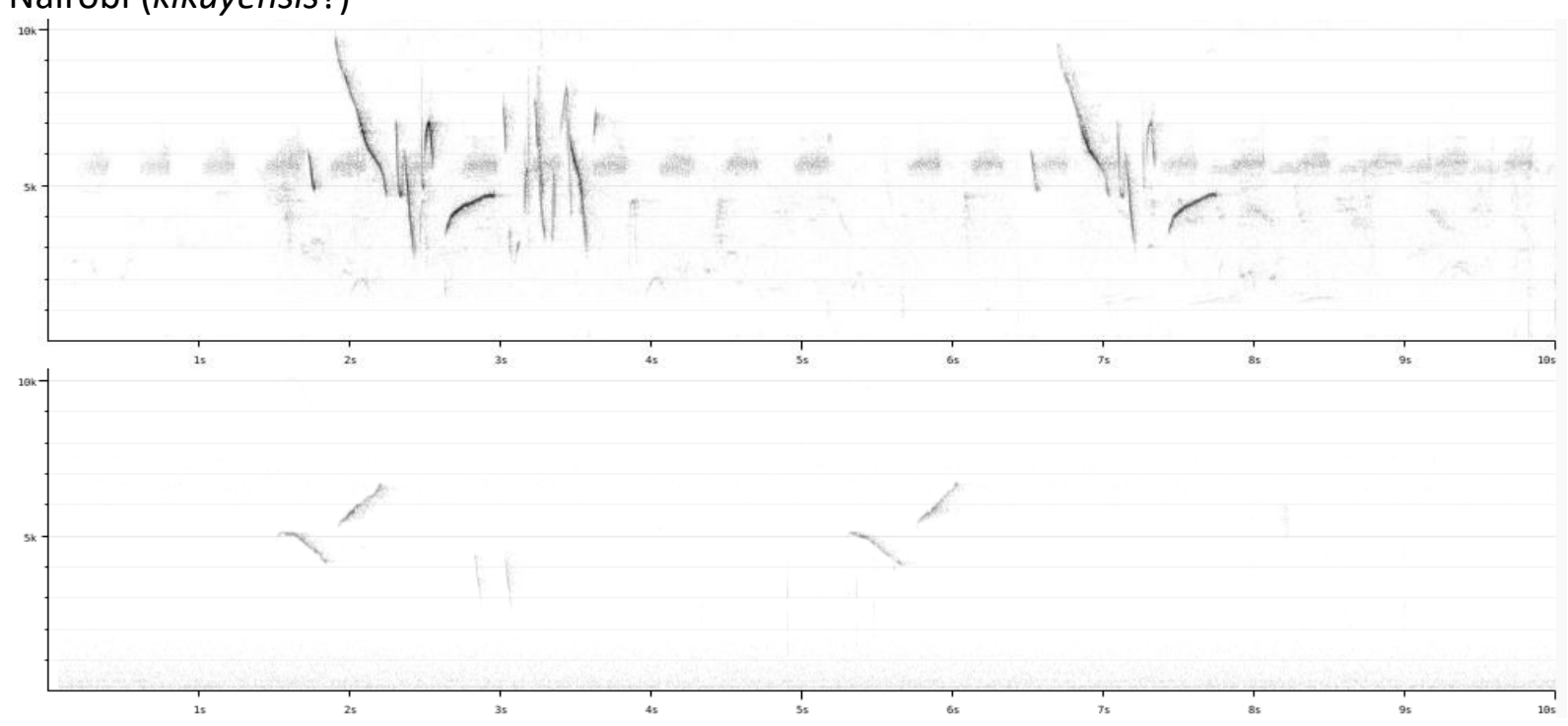




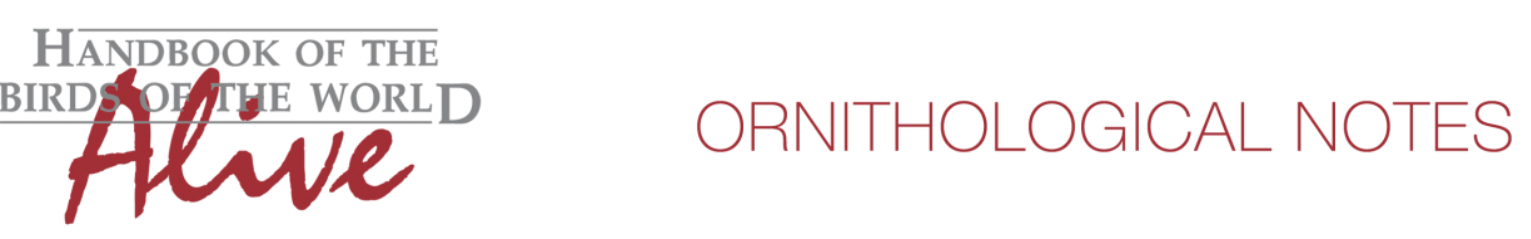

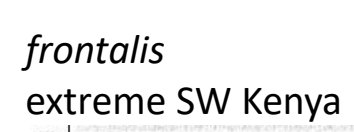

Fithl whe int?

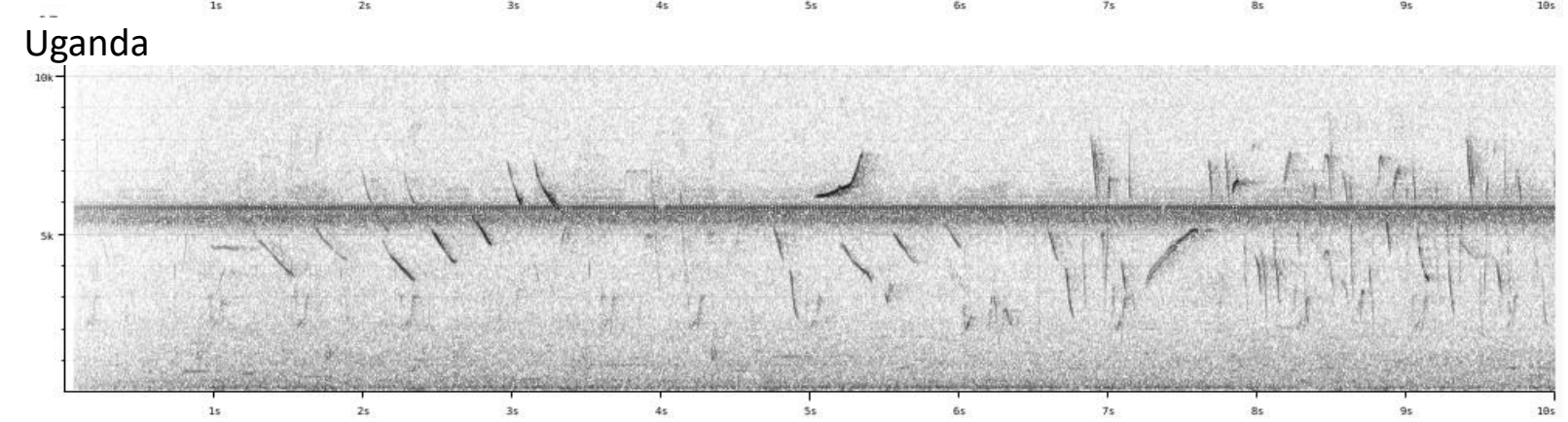

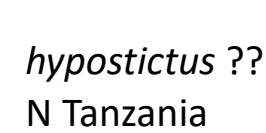

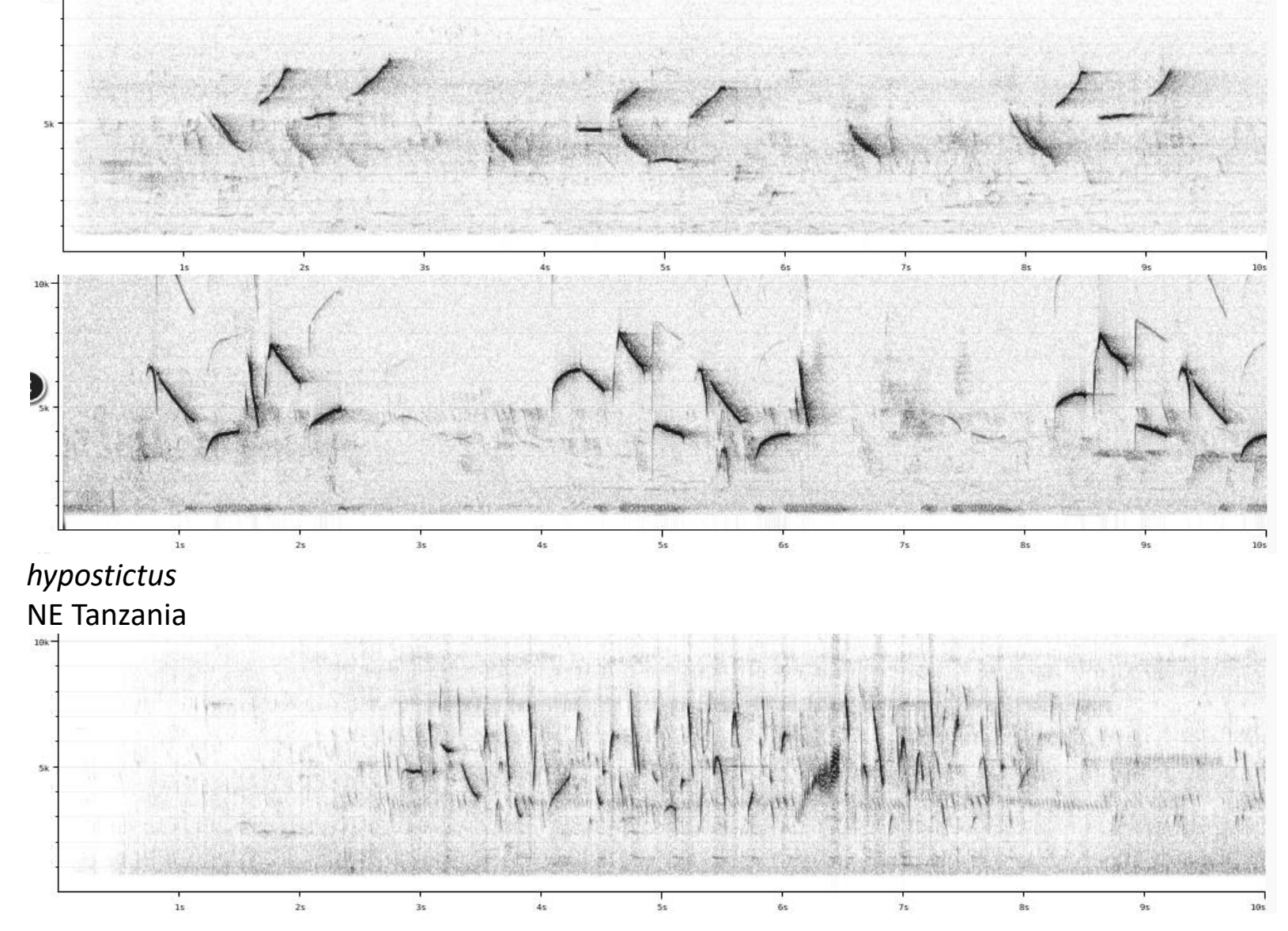




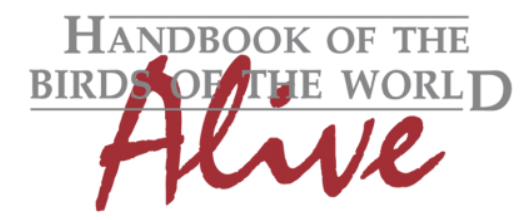

\section{ORNITHOLOGICAL NOTES}
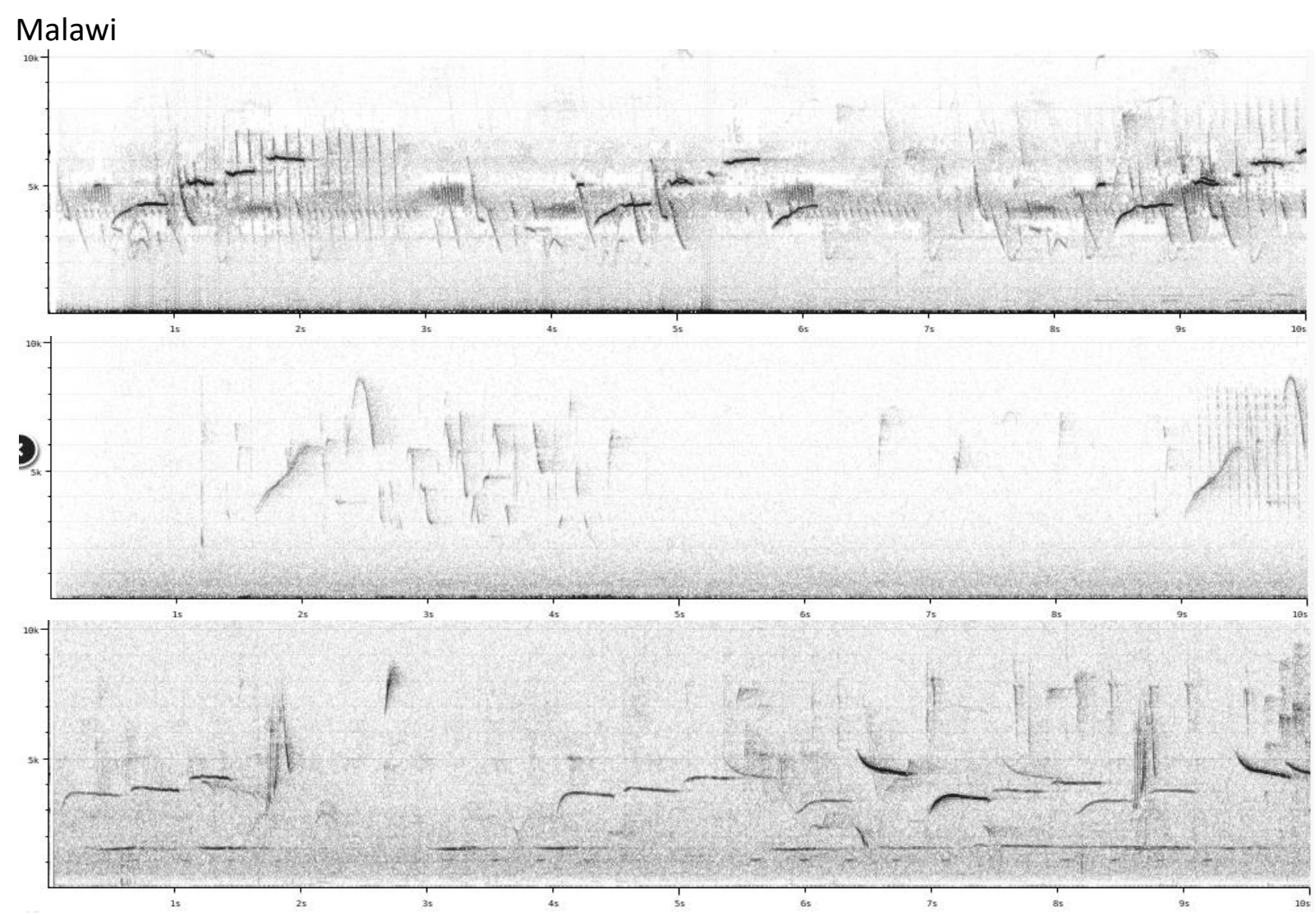

There are no recordings available of race brittoni.

With the few available recordings, no firm conclusions can be drawn (also taking into account the uncertainty of e.g. race in N Tanzania).

It would seem that:

* nominate and kikuyensis have a simple song mainly consisting of some pure rising or falling whistles.

* frontalis has a fast twittering song consisting mainly of short notes, with only a few slurred whistles thrown in.

* hyposticta has 2 song types, a fast twittering song (rather similar to frontalis) and a simple song with many slurred notes (rather like nominate/kikuyensis, but notes at flatter pitch, at least in Malawi).

These conclusions seem to be in reasonable accordance with voice description in 'Birds of Africa' (Fry et al. 2004):

Western - Song very different from African Citril, a high-pitched jingle at moderate speed, with short sweet notes mixed with thin 'sit-sit' and frequent buzzy 'zwee'.

Southern - Rapid tinkling song like Yellow-crowned Canary (Serinus flavivertex) but includes nuzzy 'zwee' and liquid 'woy' notes. Another song, 3-4 sweet notes, 'see-si-see-woo' (last note lower), or ascending 'way-peetee', like African Citril but higher-pitched. 
Based on the available recordings, there is a clear indication that there are three vocal groups. More recordings are needed however to support this statement.

This note was finalized on 22nd May 2016, using sound recordings available on-line at that moment. We would like to thank in particular the sound recordists who placed their recordings for this species on XC and ML: Peter Boesman, James Bradley, Josh Engel, Frank Lambert, Linda Macaulay, David Moyer, Rory Nefdt, Bram Piot, Andrew Spencer and Martin St-Michel.

\section{References}

Fry, C.H. \& Keith, S. eds. (2004). The Birds of Africa. Vol. 7. Sparrows to buntings. Christopher Helm, London.

Tobias, J.A., Seddon, N., Spottiswoode, C.N., Pilgrim, J.D., Fishpool, L.D.C. \& Collar, N.J. (2010). Quantitative criteria for species delimitation. Ibis 152(4): 724-746.

\section{Recommended citation}

Boesman, P. (2016). Notes on the vocalizations of African Citril (Serinus citrinelloides). HBW Alive Ornithological Note 355. In: Handbook of the Birds of the World Alive. Lynx Edicions, Barcelona. (retrieved from http://www.hbw.com/node/1252892 on 27 October 2016). 